\title{
Slow population rhythms emerge in noisy inhibitory network models
}

\author{
Ernest CY Ho*1,2, Liang Zhang1,3 and Frances K Skinner ${ }^{1,2,3,4}$
}

\begin{abstract}
Address: ${ }^{1}$ Toronto Western Research Institute, University Health Network, Toronto, Ontario, Canada, ${ }^{2}$ Departments of Physiology, University of Toronto, Toronto, Ontario, Canada, ${ }^{3}$ Departments of Medicine (Neurology), University of Toronto, Toronto, Ontario, Canada and ${ }^{4}$ Institute of Biomaterials and Biomedical Engineering, University of Toronto, Toronto, Ontario, Canada

Email: Ernest CY Ho* - ecy.ho@utoronto.ca

* Corresponding author
\end{abstract}

from Eighteenth Annual Computational Neuroscience Meeting: CNS*2009

Berlin, Germany. 18-23 July 2009

Published: 13 July 2009

BMC Neuroscience 2009, I0(SuppI I):PI56 doi:10.1186/I47I-2202-I0-SI-PI56

This abstract is available from: http://www.biomedcentral.com/I47I-2202/I0/SI/PI56

(c) 2009 Ho et al; licensee BioMed Central Ltd.

Inhibitory, interneuronal networks are known to underlie high-frequency (gamma, 40-80 Hz) population oscillations, and they are also known to underlie low-frequency rhythms. For example, spontaneous, slow $(0.5-4 \mathrm{~Hz})$ rhythms occur in rodent hippocampus [1]. However, it is unclear whether an inhibitory network can generate population oscillations much slower than the intrinsic firing frequencies of its consitutent neurons. Here we show that an inhibitory network model in the absence of any slow processes is able to produce low-frequency rhythms. To obtain this, we bridge our network model simulations with a dynamical mean-field (DMA) model [2] to approximate the location of relevant parameter regimes.

The individual interneuron model is a two-dimensional conductance-based model and the network is formed with fast, inhibitory $\mathrm{GABA}_{\mathrm{A}}$ type synapses. The DMA

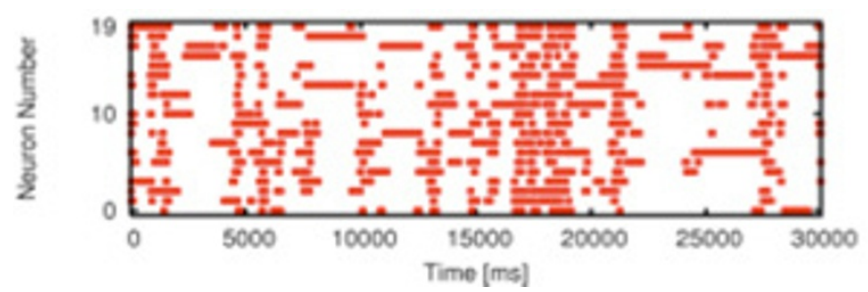

Figure I

Slow Network Rhythm. model representing a large all-to-all coupled system consists of 30 equations that include equations describing synaptic noises. Bifurcation analysis is used to explore the DMA model, in particular, to identify parameter regimes for which bursting activities occur. These parameters are used in network simulations. The network model consists of an all-to-all coupled network of 20 interneurons. Each interneuron is described by: $C d V / d t=I_{\text {app }}+b \eta-g_{L}\left(V-E_{L}\right)-$ $g_{\mathrm{Na}} m\left(V-E_{\mathrm{Na}}\right)-g_{\mathrm{K}} n\left(V-E_{\mathrm{K}}\right)-g_{\text {syn }}\left(V-E_{\text {syn }}\right) \sum_{\mathrm{i}} s_{\mathrm{i}} ; m(V)=1 /(1+\exp (-$ $4 / 3-V / 15)) ; d n / d t=1 /(1+\exp (-5-V / 5))-n ; d s_{i} / d t=a\left(1-s_{i}\right) /$ $\left(1+\exp \left(-V_{i} / 2\right)\right)-s_{i} / \tau$, where $\Sigma_{i} s_{i}$ sums the (inhibitory) synaptic gating variables from other interneurons in the network, $\eta$ represents white noise of unit strength and $b$ represents the strength of the noise. Figure 1 shows a raster plot from a 30 second network simulation (left) with the corresponding average summated synaptic activities (right). The parameters used are taken from identified

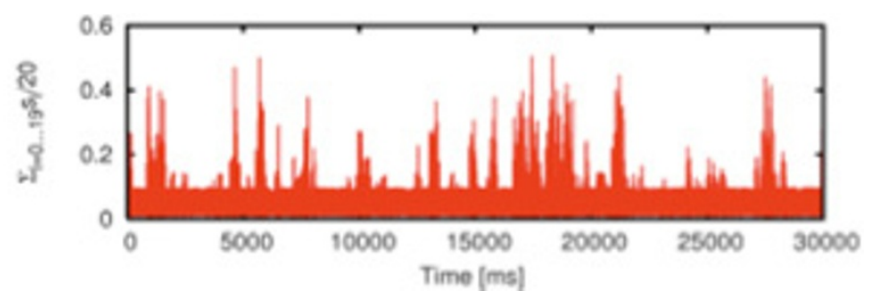


bursting regimes in the DMA model analysis. Parameters values: $I_{\mathrm{app}}=4.8 \mu \mathrm{A} / \mathrm{cm}^{2} ; b=0.08 \mathrm{~ms}^{1 / 2} \mathrm{~mA} / \mathrm{cm}^{2} ; g_{L}=8 \mathrm{mS} /$ $\mathrm{cm}^{2} ; g_{\mathrm{K}}=10 \mathrm{mS} / \mathrm{cm}^{2} ; g_{\mathrm{Na}}=20 \mathrm{mS} / \mathrm{cm}^{2} ; g_{\text {syn }}=0.0263 \mathrm{mS} /$ $\mathrm{cm}^{2} ; E_{L}=-80 \mathrm{mV} ; E_{\mathrm{K}}=-90 \mathrm{mV} ; E_{\mathrm{Na}}=60 \mathrm{mV} ; E_{\mathrm{syn}}=-85 \mathrm{mV}$; $\tau=10 \mathrm{~ms} ; C=1 \mu \mathrm{F} / \mathrm{cm}^{2}$. The intrinsic firing frequency at $I_{\text {app }}=4.8 \mu \mathrm{A} / \mathrm{cm}^{2}$ for these neurons (with zero noise) is 52 Hz. Slow population rhythms (approx $0.5 \mathrm{~Hz}$ ), or bursts of synaptic activities, can be seen to emerge due to a "switching" between sparsely firing and coherently firing network states.

A DMA model analysis has been used to find parameter regimes that allow slow rhythms to be expressed by inhibitory network models. These regimes are identified by bursting activities in a simpler mean-field model. Given the bridging used between the DMA model and the network simulations, we expect that this slow pattern should also occur in much larger network models. We have previously obtained values for synaptic "noise" parameters underlying slow hippocampal rhythms [3]. It will be interesting to determine whether bursting in the DMA models, and thus slow population rhythms in large network simulations, occur using these experimentally-based synaptic noise parameter values. If so, this would suggest a novel way in which slow rhythms could emerge in biological, inhibitory networks.

\section{Acknowledgements}

NSERC of Canada.

\section{References}

I. Wu C, Luk WP, Gillis J, Skinner F, Zhang L: Size does matter: Generation of intrinsic network rhythms in thick mouse hippocampal slices. J Neurophysiol 2005, 93:2302-2317.

2. Hasegawa $\mathrm{H}$ : Dynamical mean-field theory of spiking neuron ensembles: Response to a single spike with independent noises. Phys Rev E 2003, 67:041903.

3. Ho ECY, Zhang L, Skinner FK: Inhibition dominates in shaping spontaneous CA3 hippocampal network activities in vitro. Hippocampus 2009, 19:152-165.
Publish with Bio Med Central and every scientist can read your work free of charge

"BioMed Central will be the most significant development for disseminating the results of biomedical research in our lifetime. " Sir Paul Nurse, Cancer Research UK

Your research papers will be:

- available free of charge to the entire biomedical community

- peer reviewed and published immediately upon acceptance

- cited in PubMed and archived on PubMed Central

- yours - you keep the copyright

Submit your manuscript here:

http://www.biomedcentral.com/info/publishing_adv.asp
BioMedcentral 